\section{Transient visual changes associated with repetitive transcranial magnetic stimulation of the dorsolateral prefrontal cortex in cases of major depression}

Alterações visuais transitórias associadas à estimulação magnética transcranial repetitiva do córtex pré-frontal dorsolateral na depressão maior

\section{Dear Editor,}

In the last few years, the efficacy of repetitive transcranial magnetic stimulation (rTMS) for the treatment of depression has been increasingly investigated. ${ }^{1}$ One of the main advantages of this treatment is the benign profile of adverse effects as compared to treatment with antidepressants. However this knowledge is based on small clinical trials of short duration - usually with follow-up periods of no longer than 2 months. Therefore, rare, but potentially harmful, adverse events might not be known. In this case series study, we report the cases of two patients with major depression who developed transient visual changes after rTMS of the left dorsolateral prefrontal cortex (DLPFC). To our knowledge, this effect has never before been reported.

Case 1: Ms. E. received 20 sessions of high-frequency $(5-\mathrm{Hz})$ TMS to the left DLPFC for the treatment of depression at the age of 51. After the treatment, Ms. E. began to complain of difficulties with her near and distance vision. A subsequent ophthalmologic examination revealed no signs of ocular pathology and only a mild hyperopic shift of $+0.50 \mathrm{D}$ in both eyes (compared to the examination before rTMS treatment). Neurological examination including visual field assessment did not reveal any focal defects. Over the course of the following weeks, Ms. E. recovered her baseline vision using her habitual, corrective lenses. A third ophthalmologic examination confirmed that her refractive status was the same as her baseline (pre-TMS) examination.

Case 2: Ms. O. had a long history of depression and received one session of low-frequency (1-Hz) left-DLPFC TMS (1200 pulses) at the age of 67 . This patient had a medical history of monocular visual field defects secondary to repeated episodes of retinal detachment and had been submitted to an ophthalmologic examination 6 months prior. After the TMS session, she reported an increase in her visual field. She therefore underwent an additional neuro-ophthalmologic examination, which revealed no new ophthalmologic alterations compared to the previous examination. This condition (widening of the field of vision) was short-lived and disappeared after 3 days.

\section{Discussion}

There is some evidence to suggest that the rTMS treatment was responsible for the visual changes observed: 1) the absence of new ophthalmologic or neurological alterations; 2) the temporal relationship between the rTMS treatment and the visual changes. Because there are connections between the DLPFC and the higher level visual cortical areas, ${ }^{2-3}$ rTMS modulation of DLPFC activity might result in secondary modulation of these visual areas. Such "networking" between the prefrontal and parietooccipital cortices has been previously demonstrated. ${ }^{4}$ The opposite behavioral effects (worsening and enhancement of vision) observed in these two cases suggest that low-frequency, inhibitory rTMS of the left DLPFC enhances visual function, whereas highfrequency, facilitatory rTMS of the same region has the opposite effect. Finally, the manifestation of these symptoms in these patients might have been precipitated by their pre-existing visual deficits, i.e. their visual neural networks might have been working at maximum capacity to compensate for the peripheral deficits. Therefore, any small change in this system would upset this delicate balance and cause behavioral changes. In conclusion, we hope that this will alert clinicians to a previously unreported adverse effect of rTMS treatment.

Marco Antonio Marcolin Psychiatry Institute, Universidade de São Paulo (USP), São Paulo (SP), Brazil

José Lucas de Souza Filho Ophthalmology Department, Universidade Federal de São Paulo (UNIFESP), São Paulo (SP), Brazil

Manoel Jacobsen Teixeira Neurology Department, Universidade de São Paulo (USP), São Paulo (SP), Brazil

Felipe Fregni Harvard Center for Non-Invasive Brain Stimulation, Beth Israel Deaconess Medical Center, Harvard Medical School, Boston, USA

Financing: None

Conflict of interests: None

\section{References}

1. Gershon AA, Dannon PN, Grunhaus L. Transcranial magnetic stimulation in the treatment of depression. Am J Psychiatry. 2003;160(5):835-45.

2. Corbetta M, Kincade JM, Shulman GL. Neural systems for visual orienting and their relationships to spatial working memory. J Cogn Neurosci. 2002;14(3):508-23.

3. Turatto M, Sandrini M, Miniussi C. The role of the right dorsolateral prefrontal cortex in visual change awareness. Neuroreport. 2004;15(16):2549-52.

4. Paus T, Jech R, Thompson CJ, Comeau R, Peters T, Evans AC. Transcranial magnetic stimulation during positron emission tomography: a new method for studying connectivity of the human cerebral cortex. J Neurosci. 1997;17(9):3178-84. 